\title{
Where do our priorities lie?
}

\author{
Stephen B Hanauer
}

According to the authors of The future of drug safety: promoting and protecting the health of the public, the FDA and its Center for Drug Evaluation and Research (CDER) are severely underfunded, yet they are charged with regulating products that collectively constitute $25 \%$ of the US gross domestic product (JAMA [2007] 297:1917-1920).

The US Prescription Drug User Fee Act (PDUFA) was enacted by President George HW Bush in 1992, at a time when the FDA budget for the CDER was $\$ 126$ million and the agency was having difficulty evaluating new drugs in an efficient manner. Since then, the FDA's funding for the CDER has increased, to more than $\$ 400$ million in 2004 , and user fees, which currently account for $\sim 40 \%$ of the funding, are expected to reach $\$ 438$ million in 2008 (N Engl J Med [2007] 356: 1697-1700).

The PDUFA has successfully expedited new drug approvals, such that the US has "....increasingly become the country of first launch (as) the public testing ground for new medicines." (JAMA [2007] 297:1917-1920). By contrast, the monitoring of drug safety has not undergone synchronous enhancement. Despite initial FDA approval, the absence of an active population-based drugsurveillance system means that many drugs might be used by millions of patients before risks become evident. Indeed, $20 \%$ of drugs receive black-box warnings after approval and $4 \%$ of drugs are withdrawn from the market for safety reasons ( $N$ Engl $J$ Med [2007] 356: 1703-1704).

Pressure from industry (the users) meant that for 5 years after the PDUFA was enacted user fees could not be spent on adverse-effects surveillance. Since the PDUFA was reauthorized in 2002, the FDA applies $~ 5 \%$ of user fees to monitor post-approval drug safety ( $N$ Engl $J$ Med [2007] 356: 1703-1704), and proposes that, after $2007,7 \%$ of user fees be used to strengthen the capacity for adverse-effects ...we need

to empower

the FDA with

the resources

and authority

to enhance

drug-safety

monitoring

SB Hanauer is Editorin-Chief of Nature Clinical Practice Gastroenterology \& Hepatology.

\section{Competing interests}

The author declared he has no competing interests.

Reprinted from Hanauer SB (2007) Nat Clin Pract

Gastroenterol Hepatol 4: 353

www.nature.com/clinicalpractice doi:10.1038/ncpgasthep0868 surveillance (N Engl J Med [2007] 356: 1697$1700)$. This $\$ 29-30$ million needs to be put into perspective with the fact that $\$ 189$ billion was spent on prescription drugs in the US in 2004 at the same time that the pharmaceutical industry was spending $\$ 11.9$ billion on advertising.

The FDA currently relies on spontaneous adverse-event reports from health professionals, drug manufacturers, consumers, etc. that capture only a small fraction of adverse events. Despite the FDA's request for postmarketing studies, less than $25 \%$ of pharmaceutical companies' commitments to these (involving 1,259 studies of drugs and 373 studies of biologics) are in progress and on schedule (N Engl J Med [2007] 356: 16971700). The FDA currently lacks the systematic approach, finances and manpower needed to monitor these commitments. Had such a systematic approach been in place, it is estimated that the increased signal of serious cardiovascular risk could have been detected after less than 3 months' experience with rofecoxib (N Engl J Med [2007] 356: 17001702). Yet, during the 5 -year marketing of rofecoxib in the US, $\$ 2.5$ billion/year was being spent on the drug ( $\sim 1$ billion by Medicare). The FDA has yet to specify how the \$29-30 million generated by the likely renewal of the PDUFA will be spent amongst the myriad of tasks related to drug safety.

It is likely that the PDUFA will be reauthorized in September 2007 because it is unlikely that Congress will find alternative funding for the FDA's expanding budget. Without entering the debate as to whether funding should come from industry or from other public sources, we need to empower the FDA with the resources and authority to enhance drug-safety monitoring. The US is currently spending approximately $\$ 2$ billion/week on the Iraq war and, as Jerry Avorn reminds us, "A nation as wealthy as ours can afford what it chooses to afford." (N Engl J Med [2007] 356: 1697-1700). 